\title{
Looking Back and Beyond Sendai: 25 Years of International Policy Experience on Disaster Risk Reduction
}

\author{
Sálvano Briceño
}

Published online: 25 February 2015

(c) The Author(s) 2015. This article is published with open access at Springerlink.com

\begin{abstract}
The evolution in knowledge and application of disaster risk reduction in the 25 years of global cooperation on this issue has been uneven. While advances in knowledge have improved our understanding of the full nature of risk - the combination of hazards meeting vulnerabilitythe application of such knowledge has not been conducive to the development of institutional and technical mechanisms to address the full range of risk elements. Governance of risk (policies, legislation, and organizational arrangements) still focuses largely on preparing to respond to the hazards and planning for recovery. This leaves largely unattended the vulnerability component of risk, which is the only component on which change can be effected. Governance arrangements, risk assessments, early warning systems, and other institutional and technical capacities still concentrate on natural hazards and this is the main change that remains to be substantively addressed.
\end{abstract}

Keywords Climate change adaptation - Disaster risk reduction - Risk governance - Risk management

\section{Introduction}

In the 10 years following the adoption of the Hyogo Framework for Action (2005-2015): Building the

\footnotetext{
S. Briceño $(\square)$

Science Committee, Integrated Research on Disaster Risk (IRDR) Program of International Council for Science (ICSU)/ International Social Science Council (ISSC)/United Nations International Strategy for Disaster Reduction (UNISDR). Former Director of the Secretariat of the United Nations International Strategy for Disaster Reduction (UNISDR), http://www.irdrinternational.org/

e-mail: salvanob@gmail.com
}

Resilience of Nations and Communities to Disasters (HFA) (UNISDR 2005), we have witnessed an acceleration in the formulation and implementation of policies and measures whose goals envisage reducing the risk related to natural hazards (phenomena or events). These polices are frequently complemented with multiple actions that include awareness-raising campaigns, risk assessments, early warning systems, emergency response capacities, and so on. At national and local levels, most countries, have developed legislation, policies, programs, and projects to address the increasing disaster risk threat to humanity.

The most serious aspect of the threat is the rapid increase in exposure and vulnerability of populations, particularly those in urban areas to natural events, which themselves are increasing but at a much lower speed. Hence, the need to address the disaster risk issue with terms other than "natural disasters." This reorientation in terminology is essential to avoid creating a misunderstanding of the problem. The concept behind this shift in terminology is that the phrase "natural disasters" conveys the perception that if disasters are natural there is little that can be done, except by preparing to respond to them, instead of reducing vulnerability and building resilience, which need to be the focus of risk reduction and management policies. This is why scholars increasingly try to avoid speaking about "natural disasters" and rather refer only to "disasters" or "natural hazards." When needed, reference to "disasters triggered by natural hazards" or, more specifically, "disasters due to vulnerability to natural hazards" are the preferred expressions. This terminology revision was an essential component in the negotiations for the HFA. For many government authorities, it has been convenient to blame disasters on nature, hence their preference for maintaining the term "natural disasters." Despite official reluctance, "natural disaster" is no longer 
utilized in the HFA document, except in a footnote to explain why it should not be used.

Despite considerable progress in recent years, in particular on capacities to respond to emergencies, in recovery efforts and hazard early warning systems, ${ }^{1}$ much still remains to be done. The upcoming Third World Conference on Disaster Risk Reduction (WCDRR-3) (UN 2015) in Sendai will hopefully address current obstacles and shortcomings and provide guidance for further implementation of risk reduction policies and measures by nations and communities around the world. In particular, those populations and regions that remain most exposed and vulnerable to natural hazard impacts need emphasis in the effort to reduce social vulnerabilities and promote appropriate risk governance mechanisms. The negotiations leading to Sendai have produced valuable material from which government delegations can decide on priorities (UNISDR 2014). Information on the current state of the Post-2015 Framework for Disaster Risk Reduction as well as preparations for the conference is readily available (UN 2015).

\section{Priorities in Disaster Risk Management}

Without undertaking an exhaustive analysis of the conference's current negotiating text, I wish to highlight what in my view are the most relevant current priorities in disaster risk management (DRM). These are the issues that are still not fully addressed by the WCDRR-3 negotiations or rather are dealt with in too general terms. In my view, two fundamental questions should be addressed.

\subsection{Balancing Implementation Pace with Accelerating Need}

Although the speed with which disaster risk reduction (DRR) policies and measures have been implemented has accelerated enormously in the last 10 years, it is clear that these accelerated gains are still not proportionate to the rate at which global vulnerability to natural hazards is growing. ${ }^{2}$ DRR programs are being conceived and implemented around the world, but development investments in all fields (infrastructure, housing, agriculture, health, education,

\footnotetext{
1 The biennial UNISDR Global Assessment Reports on DRR recorded such advances in details, although mostly based on official government reports (UNISDR, n.d.a).

${ }^{2}$ Many assessments are regularly carried out at the global level, which include assessments of vulnerability growth, in addition to those done at the local, national, and regional levels. Some of the main reports in this regard, in addition to the biennial UNISDR Global Assessment Reports, are UNU (2014), IFRC (2014), and GNDR (2013).
}

energy, tourism, and so on) continue, to a large extent, to reinforce old, or create new, types of vulnerabilities at a much faster pace. It is comparable to wanting to fight the Ebola virus with simple hygiene measures.

Although the scale of investments allocated to DRR, insignificant when compared to the magnitude of the task, is part of the problem, a much greater issue is posed by a lack of understanding of the need to include appropriate risk management tools in development policies and investments. This risk management effort does not always require additional or huge funding; it simply means doing things differently, with greater risk awareness. Far more unsustainable development is being carried out than development conceived with a sustainable approach, that is, with consideration of risk impact assessments. This is a huge task, which needs to be undertaken by governments and the private sector in a massive manner. The task is on a scale comparable to the inclusion of environmental impact assessments (EIAs) ${ }^{3}$ that developed during the 1960s, and are now recognized as an indispensable component in development projects.

\subsection{Examining Risk Reduction Policies and Measures}

When assessing risk related to natural events or providing early warnings, the focus remains on the wrong side of the equation. We know that risk is created by natural hazards (phenomena or events) encountered by populations that are exposed and vulnerable. We also know that there is little that can be done with regard to the natural events or hazards, and that policy-related action should mainly aim to reduce the social vulnerability that encompasses a number of human, social, economic, ecological, institutional, physical, and other elements. From a positive perspective, the goal is to build resilience to these hazards.

Despite improvement in fundamental knowledge about nature-society relationships, most action (from policy to research, awareness, and education), still addresses either the assessment of the natural events, wrongly referring to them as "natural disasters," or the need for preparedness in order to respond in case of emergency. Not only are most institutional capacities (governance) still aimed at improving natural event preparedness efforts, ${ }^{4}$ but also the resources allocated to DRM are mainly invested in such

\footnotetext{
3 Environmental impact assessments were conceived mainly to assess the impacts of development projects on ecosystems and natural resources, and did not include consideration of natural hazards. More recently, EIAs have added consideration of natural hazards, a good example of which can be found in CDB and CARICOM (2004).

${ }^{4}$ In most countries it is still the services of civil protection or emergency management that formulate, guide, and implement policies and measures for risk reduction. A search of DRR national focal points shows this situation, see Prevention Web (n.d.).
} 
efforts. Very little effort and insufficient funds address the reduction of social vulnerabilities, which are the main cause of the heavy and negative impacts of natural hazards. The high visibility of such disasters motivates short-sighted politicians and government authorities, local and national alike, to keep huge resources available to respond (usually too late) to the emergencies. Far better would be investment beforehand to reduce vulnerability, and in this way diminish the resulting negative impacts of disaster.

From a scientific and technical perspective, much greater effort is dedicated to understanding or assessing extreme natural events, rather than social vulnerability. Risk assessments, early warning systems, and so on are tools mostly utilized to identify and prepare for the natural hazards rather than to identify, assess, and reduce social vulnerability or build resilience. Before dwelling further on these two main obstacles, a brief review of the advancements in DRR is helpful.

\section{Improvements in Disaster Risk Reduction}

For at least 50 years, it has been well known among academics specialized in risk research that the essence of any DRR policy needs to be oriented substantively towards reducing social vulnerability. It is equally well known that this effort requires an integrated approach in research, education, and policy-making. This knowledge, however, has not permeated into or made a substantive impact upon the broader academic world. The larger academic community still dedicates greater resources to a highly specialized understanding of individual natural hazards, with a greater interest on the natural process than on their social impact. The same situation characterizes the policy world, which still allocates greater resources to addressing emergency management and short-sighted recovery efforts than it devotes to reducing vulnerability or building resilience.

The United Nations undertook two fundamental initiatives relative to DDR: the International Decade on Natural Disaster Reduction (IDNDR, 1990-1999) ${ }^{5}$ and the establishment of the International Strategy for Disaster Reduction (UNISDR) in 2000. These seminal United Nations programs helped immensely to expand the DRR cause and reach a greater number of stakeholders, many of whom had not been sufficiently interested in these issues in the past. Two major milestones, the First and Second World Conferences on disaster reduction (Yokohama 1994; KobeHyogo 2005), and a number of publications ${ }^{6}$ and

\footnotetext{
5 A more detailed sequence of historic milestones can be found at UNISDR History (UNISDR, n.d.b).

${ }^{6}$ A comprehensive bibliography can be found at UNISDR Publications (n.d.c).
}

campaigns ${ }^{7}$ contributed greatly to dissemination of DRR knowledge and to implementation of policies and measures on DRR.

In the last 10 years, new networks and programs that address the needs of specific stakeholders or sectors have appeared. The nongovernmental organization (NGO) movement developed with great success the Global Network of Civil Society Organizations for Disaster Reduction (GNDR). This network sparked numerous actions in communities around the world and facilitated the exchange and dissemination of relevant manuals, videos, and other educational, awareness-raising, and technical materials. The World Bank developed, with great success, the Global Facility for Disaster Reduction and Recovery (GFDRR), which attracted substantial donor funds and provided guidance and financial resources to support actions and projects by governments, private sector institutions, NGOs, and other stakeholders.

In the scientific and academic world, a number of relevant programs have emerged that contribute to the development of further knowledge in this domain and influence research, policy, and awareness-raising applications. Some of the most relevant include: the Integrated Research on Disaster Risk (IRDR) of the International Council for Science (ICSU)/International Social Science Council (ISSC)/United Nations International Strategy for Disaster Reduction (UNISDR); the Integrated Risk Governance Project of Future Earth (IRG-Project); the Global Risk Forum (GRF); and the International Society for Integrated Disaster Risk Management (IDRiM). Many other institutions perform analogous roles at the regional level or in more specialized topic areas, such as: the Asian University Network of Environment and Disaster Management; Red de Estudios Sociales en Prevención de Desastres in Latin America and the Caribbean; the Partners Enhancing Resilience for People Exposed to Risks (PeriPeri U); and the Latin America University Network on DRR (REDULAC).

Associations working for the private sector, local governments, unions, churches, and so on have developed specific networks and undertaken activities to promote and facilitate DRR with their own members. At the same time, international organizations responsible for specific development sectors have also included DRR in their programs: United Nations Educational, Scientific and Cultural Organization (UNESCO); Food and Agriculture Organization of the United Nations (FAO); World Health Organization (WHO); United Nations Development Programme

\footnotetext{
${ }^{7}$ For several years UNISDR organized, together with other international partners, annual campaigns on specific DRR topics. See UNISDR We campaign (UNISDR, n.d.d). At present, similar campaigns are carried out frequently by many more international organizations as well as civil society organizations and governments at the local, national, and international levels.
} 
(UNDP); World Meteorological Organization (WMO); United Nations Environment Programme (UNEP); International Labour Organization (ILO); United Nations Children's Fund (UNICEF); World Food Programme (WFP); International Telecommunication Union (ITU); and many others. This list could be expanded greatly if we add the regional and subregional organizations, and would grow even further if national and local initiatives were included. $^{8}$

It is important to recognize that the advancement in knowledge, understanding, and policy action on DRR have been rather significantly, albeit unfortunately, assisted by the occurrence of highly visible disaster events, the 1985 Mexico Earthquake, 1995 Kobe Earthquake, 2004 Indian Ocean Tsunami, 2005 Katrina Hurricane, and more recently, the 2010 Haiti Earthquake, the 2011 Great East Japan Earthquake, Tsunami, and Nuclear disaster (UNISDR, n.d.b; Munich Re, n.d.; Swiss Re, n.d.; CRED, n.d.a; CRED, n.d.b). At each of these and other similar tragic events, the public awareness that ensues has helped to move forward a bit faster consciousness and action on risk reduction.

\section{Policy at the Sendai Conference}

As the international community prepares for the WCDRR3, Sendai, 14-18 March 2015, it is essential to address the main obstacles and shortcomings in the process of reducing disaster risk in order to build resilience and significantly reduce the number of victims and social and economic impacts that are due to existing and growing vulnerability to natural hazards. There are several goals to be considered when adopting a new action plan at Sendai, later in the year when acting on new Sustainable Development Goals in New York, and at the end of the year when agreeing to a new climate change agreement at UNFCCC COP 21, at Paris.

\subsection{Integration of Risk Management into Sustainable Development Policies and Climate Change Adaptation}

The challenge is to ensure the inclusion of risk impact assessments, based on hazard and vulnerability assessments,

\footnotetext{
${ }^{8}$ The best sources of information on these initiatives are: PreventionWeb (www.preventionweb.net); United Nations International Strategy for Disaster Reduction (www.unisdr.org); Global Facility for Disaster Reduction and Recovery (www.gfdrr.org); Global Network of Civil Society Organizations for Disaster Reduction (www.glo balnetwork-dr.org); Integrated Research on Disaster Risk (www. irdrinternational.org); among others, or simply searching by the name of each organization and adding disaster risk reduction on the Internet.
}

into all development investments. Risk management is needed in each development sector (agriculture, health, infrastructure, land use, urban planning, environment, energy, tourism, education, and so on). In other words, it is important to guide and facilitate the inclusion of risk management in all development sectors as part of their own programs, rather than to vest the responsibility for risk management in a single agency, for example, emergency or disaster management services.

This implies a massive undertaking by all governments, and requires substantive awareness-raising activities to ensure that each sector becomes risk aware and adopts risk management as its own tool. The task also requires policy and technical guidance because not all DRM methodologies are equal. Each methodology depends on the specific sector involved as well as on each type of natural hazard and its intensity and frequency of recurrence. Countries or communities that are prone to seismic risk will have a different type of risk assessments than those that are prone to floods or storms. But all risk assessments will have common elements, such as institutional and educational capacities and requirements. Risk assessment methodologies usually include also physical vulnerability assessment and building and construction codes as common denominators.

Identifying and assessing risk related to natural phenomena must become an integral part of all development investment projects, be undertaken regularly at all levels with assessment of all possible hazard impacts, and recognize exposure and vulnerabilities, as well as develop resilience capacities.

\subsection{Shifting to Vulnerability Reduction and Resilience Building}

In risk assessments, usually it is the potential impact of natural phenomena that is assessed, including their frequency or recurrence interval, potential magnitude, and so on. Social vulnerability or resilience capacities are seldom or insufficiently assessed.

Rectifying this disparity undoubtedly requires a much greater and more detailed effort, which in larger urban areas most at risk can become a gargantuan task. Some major megacities have taken up this challenging task: Istanbul, Bogota, and to a lesser extent Mumbai, Manila, and the megacities of other developing and developed countries. It is a tedious but essential undertaking to ensure that disaster risk is effectively reduced. Methodologies exist that have been developed by the development banks, in particular the Inter-American Development Bank (IADB) and the World Bank, and many academic and technical institutions around the world are also engaged in developing specific risk assessment methodologies and 
capacities. ${ }^{9}$ Unfortunately, most of the current efforts still focus on identifying, understanding, and assessing the hazard component of risk and very few have addressed the social vulnerability component of risk or are doing it in a sufficiently comprehensive manner.

Equally, early warning systems, which are essential risk reduction tools, must be developed to identify not only potentially hazardous natural events, but also to determine the presence in a community of vulnerabilities: human, social, economic, ecological, institutional, and physical. The development of warning systems can provide guidance on how to develop resilience capacities able to cope with and mitigate the impacts of impending hazardous events. Two main strategic elements are needed to achieve these goals.

\subsection{Ensuring a Strong Institutional Basis for Implementing Disaster Risk Reduction}

Ten years of implementation of the Hyogo Framework for Action (HFA) have shown that great improvement has been achieved by almost all countries by having created a DRR policy or program. But these efforts have been largely carried out by existing institutions whose focus is mainly on emergency management. These agencies have developed DRR programs rather timidly and without adequate funding. A much greater effort is still required to create institutions that are placed at the highest levels of authority in government (Jackson 2011; Kellet and Sparks 2012; OECD 2012; ODI and GFDRR 2013).

Specialized, DRR-dedicated institutions must focus on identifying, assessing, and managing risk as their main task, with influence in all development sectors in order to ensure the inclusion of risk management capacities in their programs. This new type of governance, focusing on risk, needs to be independent of the traditional emergency management institutions. The capacities of these emergency agencies also need to be reinforced, since they perform an essential function and should be well resourced and competent at both the national and local levels.

\footnotetext{
9 The Global Earthquake Model (GEM) (www.globalquakemodel. org); the CAPRA Probabilistic Risk Assessment Programme (www. ecapra.org); Earthquake Megacities Initiative (http://emi-megacities. org/); Geohazards International (http://geohaz.org/home) are just a few of such initiatives, and for specific type of hazards, the CIMA Foundation in Savona, Italy (www.cimafoundation.org); the Global Volcano Model (www.globalvolcanomodel.org) at the University of Bristol, United Kingdom working with partners around the world; among others. The UNISDR Global Assessment Reports on DRR provide further information on additional efforts to develop assessment methodologies for current and potential risk around the world (www.unisdr.org/we/inform/gar).
}

Emergency management agencies cannot, however, ensure the inclusion of risk reduction approaches in all development sectors because their emphasis is on quick response to crisis rather than long-range solutions to fundamental problems.

\subsection{Developing Resilience Awareness and Consciousness-Raising}

This means the active promotion by highest levels of authority in government, as well as political, business, and community leaders, of a paradigm shift that concentrates on building resilience to natural phenomena and focuses on identifying and reducing social vulnerability as the main cause of disasters. Hence the major need is to expand awareness of and consciousness about the vulnerability elements in social systems rather than concentrate solely on the natural hazards that impact on human systems.

A main outcome of this strategic goal is to promote change in the use of the term "natural disaster," in order to explain the social character of disasters and of their main cause-social vulnerability. During the 1990s this was what the IDNDR identified as the need for a paradigm shift in this field (UN 1999). Although this shift has been happening gradually as people and institutions become increasingly more aware of the issue than in the past, the paradigm change is still moving at a pace that only enhances fears for an even more dramatic future in the relationship of humankind and nature.

In the current text being negotiated for the post-2015 framework for DRR, education and awareness-raising have been correctly identified as top priorities in public policy. The problem is that such educational efforts focus on understanding the natural phenomena involved or the actions to be undertaken in preparedness for an emergency response. Very little, and sometimes almost nothing, is done to address the vulnerabilities that put a specific community, family, or individual at risk to these natural hazards. What is it that needs to be changed in people's behavior to make them stronger to resist or be resilient to these hazards? This question should be the focus of educational and awarenessraising efforts by governments and civil society organizations. In such a consciousness process, understanding the hazards and preparing to respond are key elements. Good data, information, and knowledge about natural hazards are essential. But it is one thing to include those components and another to focus only on them. This is one of the key challenges that must be addressed at Sendai.

Educational and awareness-raising efforts are not only the task of governments, media, and civil society organizations. These tasks should become a habitual and regular feature of discussions in families and communities so that each person becomes capable of reducing risk in their daily 
activity at home, office, school, and on the street. Risk assessment and risk management are not only technical processes; they are also personal and community processes and attitudes to be integrated into our daily lives.

A good comparison can be made with prevention efforts in health policies. Wellness-support efforts do not focus on understanding viruses, microbes, or bacteria; such understanding and knowledge is left to scientific experts. The main disease prevention efforts are geared towards changing people's and communities' behavior to focus on those actions that make them stronger or more resilient, such as good nutrition, exercise, access to safe drinking water, and other aspects of personal hygiene and community conduct.

Natural hazards and their impacts can be considered to be analogs to viruses. Scientific experts need to understand viruses in depth, and the public must have a basic understanding. But risk reduction policies and measures need to be oriented towards resilience building and vulnerability reduction, that is, understanding what in our behavior makes us stronger or weaker in the effort to resist and reduce the impact of natural hazards. To a large extent the effort is about the construction techniques and the building locations where we chose (or are allowed to) build our houses, offices, schools, health centers, and infrastructure in general. The goal is to integrate risk reduction criteria and approaches in urban and land-use planning and environmental management to develop and enforce construction and building codes and zoning regulations. Just as the main aim in health and wellness programs is to make our bodies stronger and more disease resistant, in hazard prevention or DRR it is about making our buildings (homes, offices, roads, and other infrastructure) stronger, more resistant, and more resilient.

\section{Concluding Thoughts}

I trust the 2015 Sendai conference will become the major milestone in DRR, which will allow for a paradigm shift on risk reduction towards greater resilience of nations and communities to nature's behavior. More specifically, this paradigm change should allow for a substantive inclusion of risk reduction criteria and approaches in the Sustainable Development Goals that are to be adopted in New York in September 2015 and, more importantly due to its legallybinding nature, also will appear in the new agreement on climate change to be adopted in Paris in December 2015.

Open Access This article is distributed under the terms of the Creative Commons Attribution License which permits any use, distribution, and reproduction in any medium, provided the original author(s) and the source are credited.

\section{References}

CDB (Caribbean Development Bank) and CARICOM (Caribbean Community Secretariat). 2004. Sourcebook on the integration of natural hazards into the environmental impact assessment (EIA) process. Barbados: Caribbean Development Bank. http://www. caribank.org/uploads/2012/03/Source-Book5.pdf. Accessed 31 Jan 2015.

CRED (Centre for Research on the Epidemiology of Disasters). n.d.a. http://www.cred.be/. Accessed 31 Jan 2015.

CRED (Centre for Research on the Epidemiology of Disasters). n.d.b. Emergency events database (EM-DAT). http://www.emdat.be/. Accessed 31 Jan 2015.

GNDR (Global Network of Civil Society Organisations for Disaster Reduction). 2013. Views from the frontline. http://www. globalnetwork-dr.org/views-from-the-frontline/vfl-2013.html. Accessed 14 Feb 2015.

IFRC (International Federation of Red Cross and Red Crescent Societies). 2014. World disaster report. http://www.ifrc.org/en/ publications-and-reports/world-disasters-report/world-disastersreport/. Accessed 14 Feb 2015.

Jackson, D. 2011. Effective financial mechanisms at the national and local level for disaster risk reduction (paper written for the midterm review of the UNISDR Hyogo Framework for Action). http://www.preventionweb.net/files/18197_202jackson.financial mechanismstosup.pdf. Accessed 14 Feb 2015.

Kellet, J., and D. Sparks. 2012. Disaster risk reduction: Spending where it should count. http://www.globalhumanitarianassistance. org/wp-content/uploads/2012/03/GHA-Disaster-Risk-Report.pdf. Accessed 14 Feb 2015.

Munich Re. n.d. NatCatSERVICE Download center for statistics on natural catastrophes. http://www.munichre.com/en/reinsurance/ business/non-life/natcatservice/index.html. Accessed 31 Jan 2015.

ODI (Overseas Development Institute) and GFDRR (Global Facility for Disaster Reduction and Recovery). 2013. Financing disaster risk reduction: A 20 year story of international aid. http://www. odi.org/sites/odi.org.uk/files/odi-assets/publications-opinion-files/ 8574.pdf. Accessed 14 Feb 2015.

OECD (Organisation for Economic Co-operation and Development). 2012. Disaster risk assessment and risk financing: A G20/OECD methodological framework. http://www.oecd.org/gov/risk/G20dis asterriskmanagement.pdf. Accessed 14 Feb 2015.

PreventionWeb. n.d. Countries, territories \& regions. http://www. preventionweb.net/english/countries. Accessed 31 Jan 2015.

Swiss Re. n.d. Sigma: Insurance research. http://www.swissre.com/ sigma/\#inline. Accessed 31 Jan 2015.

UN (United Nations). 1999. International Decade for Natural Disaster Reduction Proceedings of the Programme Forum. Geneva, 5-9 July 1999. http://www.unisdr.org/files/31468_programmeforum proceedings.pdf. Accessed 14 Feb 2015.

UN (United Nations). 2015. World Conference on Disaster Risk Reduction. http://www.wcdrr.org/. Accessed 31 Jan 2015.

UNISDR (United Nations International Strategy for Disaster Reduction). n.d.a. Global assessment report. www.unisdr.org/we/ inform/gar. Accessed 31 Jan 2015.

UNISDR (United Nations International Strategy for Disaster Reduction). n.d.b. History. http://www.unisdr.org/who-we-are/history. Accessed 31 Jan 2015.

UNISDR (United Nations International Strategy for Disaster Reduction). n.d.c. Publications. http://www.unisdr.org/we/inform/pub lications? $\mathrm{by}=2 \& \mathrm{o}=\mathrm{asc}$. Accessed $14 \mathrm{Feb} 2015$.

UNISDR (United Nations International Strategy for Disaster Reduction). n.d.d. We campaign. http://www.unisdr.org/we/campaign. Accessed 14 Feb 2015. 
UNISDR (United Nations International Strategy for Disaster Reduction). 2005. Hyogo framework for action (2005-2015): Building the resilience of nations and communities to disasters. http:// www.unisdr.org/2005/wcdr/intergover/official-doc/L-docs/Hyogoframework-for-action-english.pdf. Accessed 1 Feb 2015.

UNISDR (United Nations International Strategy for Disaster Reduction). 2014. Development of the post-2015 framework for disaster risk reduction. Zero draft submitted by the co-Chairs of the Preparatory Committee (20 October 2014). http://www. wcdrr.org/preparatory/post2015. Accessed 31 Jan 2015.

UNU (United Nations University). 2014. World risk report. http:// worldriskreport.entwicklung-hilft.de/uploads/media/WorldRisk Report_2014_online-II_01.pdf. Accessed 14 Feb 2015. 